\title{
Justification and selection of vegetation indices to determine the early soybeans readiness for harvesting
}

\author{
Rashid Kurbanov ${ }^{1}$ and Natalia Zakharova ${ }^{1, *}$ \\ ${ }^{1}$ Federal Scientific Agroengineering Center VIM, Department of intellectualization, automation and \\ robotics of agricultural machinery production, 1-st Institutsky proezd, 109428 Moscow, Russia
}

\begin{abstract}
An unmanned aerial vehicle monitoring provides operational information on soybean harvesting readiness for breeders and agronomists. The purpose of the study is to substantiate the choice of vegetation indices to assess the content of chlorophyll a and $b$, which contribute to determining the early readiness of soybean crops for harvesting, based on data obtained from an unmanned aerial vehicle. The research was conducted at the soybean breeding field in 2020. Seven broad-band vegetation indices NDVI, NDRE, ClGreen (GCI), CCCI, CVI, GNDVI, MCARI were used in the study, estimating changes in chlorophyll $\mathrm{a}$ and $\mathrm{b}$ content in soybean leaves. Vegetation indices, which in complex testify to the early readiness of soybean crops for harvesting, have been revealed. The statistical difference between the values of the indices of early maturing and late maturing samples was calculated. The data obtained contributed to the development of custom formulas for assessing the early harvesting readiness of soybeans.
\end{abstract}

\section{Introduction}

Chlorophyll $\mathrm{a}$ and $\mathrm{b}$ and carotenoids are the main classes of photosynthetic pigments found in green vegetation. One of the main pigments, chlorophyll, absorbs solar radiation to the greatest extent in the spectral ranges of the red and blue channels. While carotenoids, including xanthophylls, absorb small amounts of solar radiation in the blue and green bands and transmit it to the reaction center of photosynthesis [1]. Green vegetation is characterized by high reflection values in the green channel, giving the leaves their characteristic color [2].

In digital agriculture, multispectral [3], thermal [4] and hyperspectral [5 - 6] cameras act as suspended equipment [7] for ground [8] and aerial vehicles [9]. In the soybean crops research, unmanned aerial vehicles (UAVs) of fixed-wing [10] and multi-rotor [11] types are used. UAVs complete with suspended equipment [12 - 13] allow obtaining accurate and high-quality data with a high spatial resolution up to 10 centimeters/pixel [14] on the state of agricultural biological objects. After processing the aerial photography data, there is the creation of an orthophotoplane, a digital terrain model and the calculation of vegetation indices, and the generation of maps for these indices.

\footnotetext{
*Corresponding author: smedia@vim.ru
} 
Researchers often use broadband vegetation indices, for example, NDRE - Normalized difference red edge index [15], CVI - Chlorophyll vegetation index, CCCI - Canopy Chlorophyll Content Index [16], ClGreen (GCI) - Chlorophyll Index Green [17], GNDVI Green Normalized Difference Vegetation Index [18], and narrow-band vegetation indices, for example, CCI - Chlorophyll/Carotenoid index [19], CARI - Chlorophyll Absorption Ratio Index [20], LCI - Leaf Chlorophyll Index [21] and others [16] to study the chlorophyll content in plants. The use of vegetation indices is popular to assess chlorophyll content, among other things, to record changes in plant photosynthetic activity [22], biomass [23] the nitrogen starvation presence [24] fixation of wilting processes [25] and plants senescence [26].

The plants' senescence process has key importance in the formation of crop yields. With the plants' premature senescence caused by unfavorable environmental conditions, a decrease in yield occurs. Senescence begins at the final stages of the annual crop growing season. At this time, chlorophyll is destroyed, leaves wither and turn yellow, seeds develop, nutrients are remobilized into seeds, so more than $70 \%$ of nitrogen enters seeds from senescent leaves [27]. It is possible to estimate the chlorophyll concentration in the leaves and assess the degree of plants senescence by measuring the absorption of light in the red and red edge ranges. According to the degree of plants senescence, breeders can assess their readiness for harvesting, for example, soybean plants are ready for harvesting when the leaves and stems turn yellow, and the seed pods turn brown or black.

There is a use of remote sensing data for phenotyping soybean crops [28 - 29], stress detection [4], predicting readiness for harvesting [27], and yield [30], determination of crop density [31]. The question of determining the early soybean crop's readiness for harvesting using a UAV has not been sufficiently disclosed. So, it is relevant to further research on this subject.

The purpose of this article is to substantiate the vegetation indices choice that contributes to the determination of the early readiness of soybean crops for harvesting, based on data obtained from a UAV and a multispectral camera.

\section{Materials and methods}

\subsection{Study Area}

The research took place on the breeding field of soybean crops ISA - a branch of the Federal Scientific Agroengineering Center VIM in the Ryazan region (54 57'95'05N, $39^{\circ} 55^{\prime} 24^{\prime \prime} 94 \mathrm{E}$ ). There were two stages for field sowing: on May 8 - the collection farm and on May 12 other plots. There were eight flights: 06/11/2020 (31 and 35 days after planting (DAP)); 06/22/2020 (42 and 46 DAP); 07/02/2020 (52 and 56 DAP); 07/17/2020 (67 and 71 DAP); 07/31/2020 (81 and 85 DAP); 08/14/2020 (95 and 99 DAP); 08/26/2020 (107 and 111 DAP) and 09/08/2020 (120 and 124 DAP) in the main phases of soybean vegetation: shoots, branching, flowering, fruit formation, seed filling, ripening. The harvesting of crops was during the period from August 27 to September 24. The total area under research was 0.9956 ha.

When analyzing the vegetative growth of soybean crops in the breeding area, researchers selected ten points, where samples No. 1 and No. 9 correspond to early ripening varieties, No. 2-8 - to medium ripening ones, and No. 10 - to late-ripening soybeans (Figure 1). The coordinates of each spot were recorded. There also was data recording of considered indices in each of the ten samples during the main phases of soybean vegetation and the indices' average values by field. 


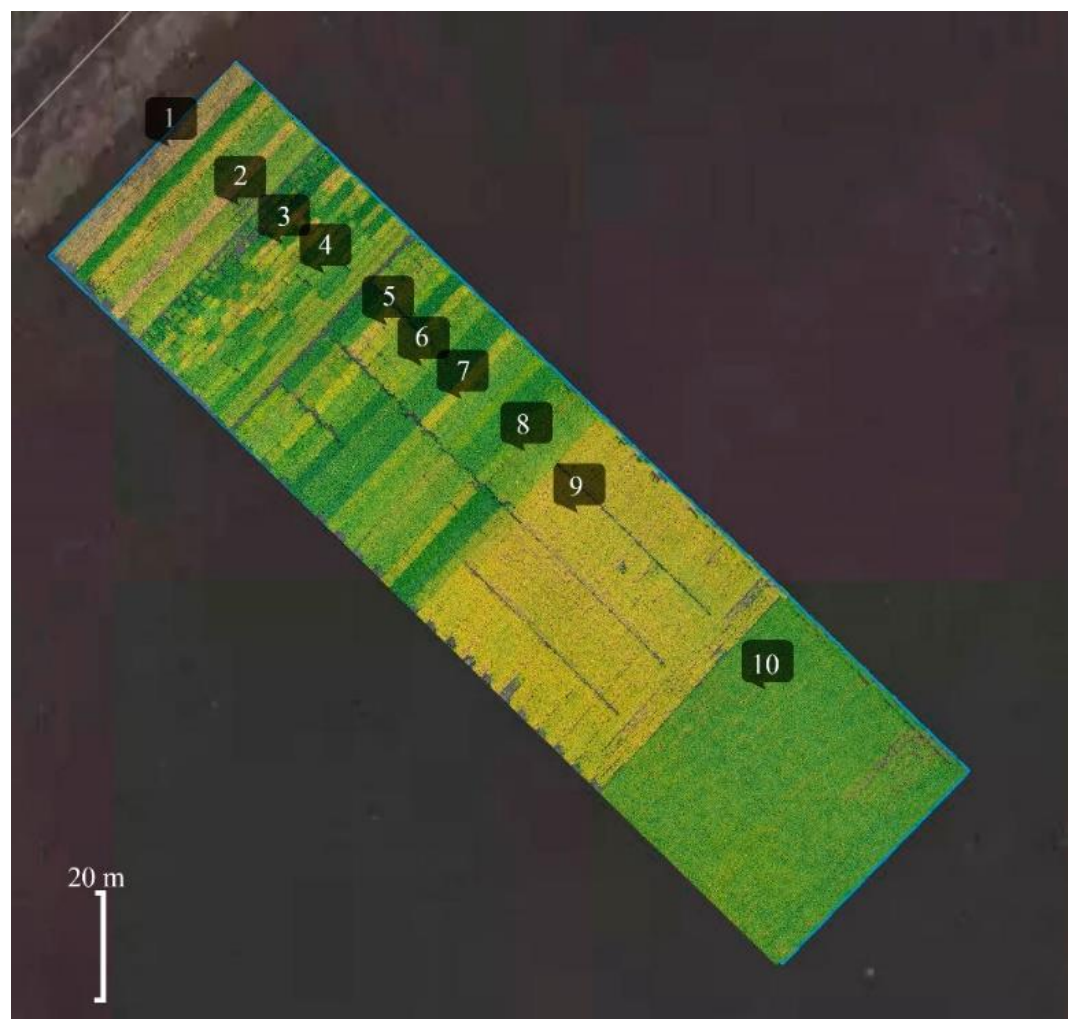

Fig. 1. Location of samples No. 1-10 on the soybean breeding field

\subsection{Weather conditions}

Breeders recorded weather conditions every day at the local weather station three times a day (at 9:00, 12:00, and 18:00). The meteorological station is located (54.58'40'02, 39.55'79'63) in the Podvyazye village, Ryazan District, Ryazan Region, Russia. They also registered the minimum, maximum, and average temperature per day and the amount of precipitation in $\mathrm{mm}$, that fell during the day. The online service (Yandex Pogoda https://yandex.ru/pogoda/) provided the average statistical data on weather conditions for the last ten years.

\subsection{Unmanned Aerial Vehicle Platform and Sensor}

A DJI Phantom 4 pro quadrocopter was used in the research (Dajiang Innovation Technology Co., China) with an attached multispectral camera Parrot Sequoia 4.0. The designed suspension, which took into account the sensors and detectors of the UAV (RU 2728846 $\mathrm{C} 1$ ), attached the camera to the drone [32]. The flights had altitudes at 70 meters during 12 minutes with a side and front overlap of $75 \%$ and $70 \%$ (Figure 2 ). 


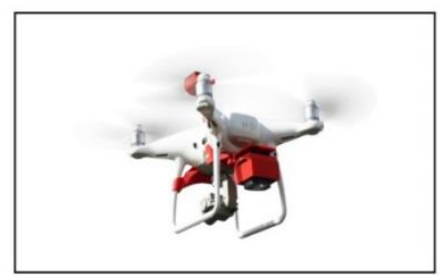

UAV DJI Phantom 4 pro

Camera $20 \mathrm{Mp}, 4864$ x 3648 px

Suspention (RU 2728846 C1)

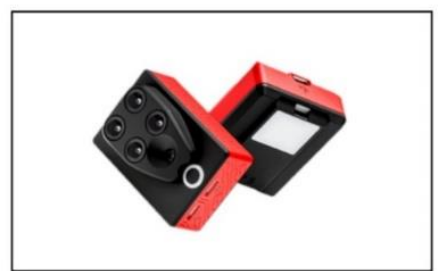

Multispectral camera

Parrot Sequoia, Sunshine sensor

GPS-receiver

$1.2 \mathrm{MP}, 1280 \times 960 \mathrm{px}$

Green $(550 \mathrm{~nm} \pm 40 \mathrm{~nm})$

$\operatorname{Red}(660 \mathrm{~nm} \pm 40 \mathrm{~nm})$

Red edge $(735 \mathrm{~nm} \pm 10 \mathrm{~nm})$

Near infrared $(790 \mathrm{~nm} \pm 40 \mathrm{~nm})$

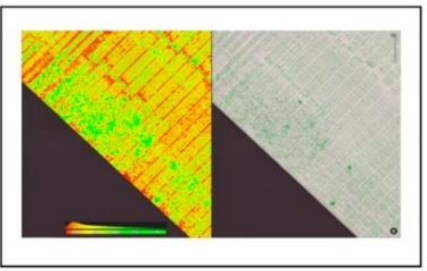

Flight hight $70 \mathrm{~m}$.

Flight time $12 \mathrm{~min}$.

Overlap $75 \%$ and $70 \%$

GSD Ortophotoplan $1.52 \mathrm{sm} / \mathrm{px}$

GSD Vegetation map $7.28 \mathrm{sm} / \mathrm{px}$

Fig. 2. Platform characteristics

\subsection{Data Processing}

For photogrammetric processing, Pix4D Mapper software, Ag Multispectral template was used. There was a creation of highly detailed orthophotoplane, a digital surface model, reflection maps, and spectral maps of seven vegetation indices (Table 1). These broadband vegetation indices were selected based on the available spectral channels and their ability to estimate the chlorophyll content in plants.

Table 1. Broadband vegetation indexes for chllorophil estimation

\begin{tabular}{|llcc|}
\hline \multicolumn{1}{|c}{ Name } & & Formula $^{*}$ & References [16] \\
\hline $\begin{array}{l}\text { Normalized } \\
\text { difference } \\
\text { vegetation index }\end{array}$ & NDVI & $\frac{\mathrm{N}-\mathrm{R}}{\mathrm{N}+\mathrm{R}}$ & Rouse et al. \\
\hline $\begin{array}{l}\text { Normalized } \\
\text { difference red edge } \\
\text { index }\end{array}$ & NDRE & $\frac{\mathrm{N}-\mathrm{RE}}{\mathrm{N}+\mathrm{RE}}$ & Caroline et al. \\
\hline $\begin{array}{l}\text { Canopy } \\
\begin{array}{l}\text { Chlorophyll } \\
\text { Content Index }\end{array}\end{array}$ & CCCI & $\frac{\mathrm{N}-\mathrm{RE}}{\mathrm{N}+\mathrm{RE}}$ & El-Shikha et al. \\
\hline $\begin{array}{l}\text { Chlorophyll } \\
\text { vegetation index }\end{array}$ & $\mathrm{CVI}$ & $\frac{\mathrm{N}-\mathrm{R}}{\mathrm{N}+\mathrm{R}}$ & Vincini et al. \\
\hline $\begin{array}{l}\text { Chlorophyll Index } \\
\text { Green }\end{array}$ & $\begin{array}{l}\mathrm{ClGreen} \\
\text { (GCI) }\end{array}$ & $\mathrm{N} \times \frac{\mathrm{R}}{\mathrm{G}^{2}}$ & Ahamed et al. \\
\hline
\end{tabular}




\begin{tabular}{|c|c|c|c|}
\hline $\begin{array}{l}\text { Green Normalized } \\
\text { Difference } \\
\text { Vegetation Index }\end{array}$ & GNDVI & $\frac{\mathrm{N}-\mathrm{G}}{\mathrm{N}+\mathrm{G}}$ & Lu et al. \\
\hline $\begin{array}{l}\text { Modified } \\
\text { chlorophyll } \\
\text { absorption in } \\
\text { reflectance index }\end{array}$ & MCARI & {$[(R E-R)-0,2 \times(R E-G)] \times \frac{R E}{R}$} & Daughtry et al. \\
\hline
\end{tabular}

*where $\mathrm{G}$ is the reflection in the green spectrum; $\mathrm{R}$ - reflection in the red spectrum; $\mathrm{RE}$ - reflection in the red edge spectrum; $\mathrm{N}$ - near-infrared reflection.

The Jenks method (Jenks natural breaks classification method) performed data clustering. This method created class boundaries in such a way as to minimize differences within a class and maximize differences between them.

In the statistical analysis, Student's t-test was used to determine the presence of differences between the values of the vegetation indices of early and late maturing soybean varieties. The breeders verified the data on the early maturity of types based on observations of the growth and development of soybean crops.

\section{Result and Discussion}

\subsection{Weather conditions}

The weather in May-September 2020 did not differ radically from the average for past years in Podvyaz. Temperature indicators were close to the average over the past ten years and differed by no more than $7^{\circ} \mathrm{C}$. At the same time, in May-August, there were extremely low and unfavorable temperatures for the development and growth of soybean crops respectively: $0.0{ }^{\circ} \mathrm{C},+8.0{ }^{\circ} \mathrm{C},+7.5{ }^{\circ} \mathrm{C},+6{ }^{\circ} \mathrm{C}$. Precipitation fell unevenly, increasing rainy periods or periods of drought, for example, in June, precipitation was $168.51 \%$ (112.9 mm.) with an average of $67 \mathrm{~mm}$ (Figure 3).

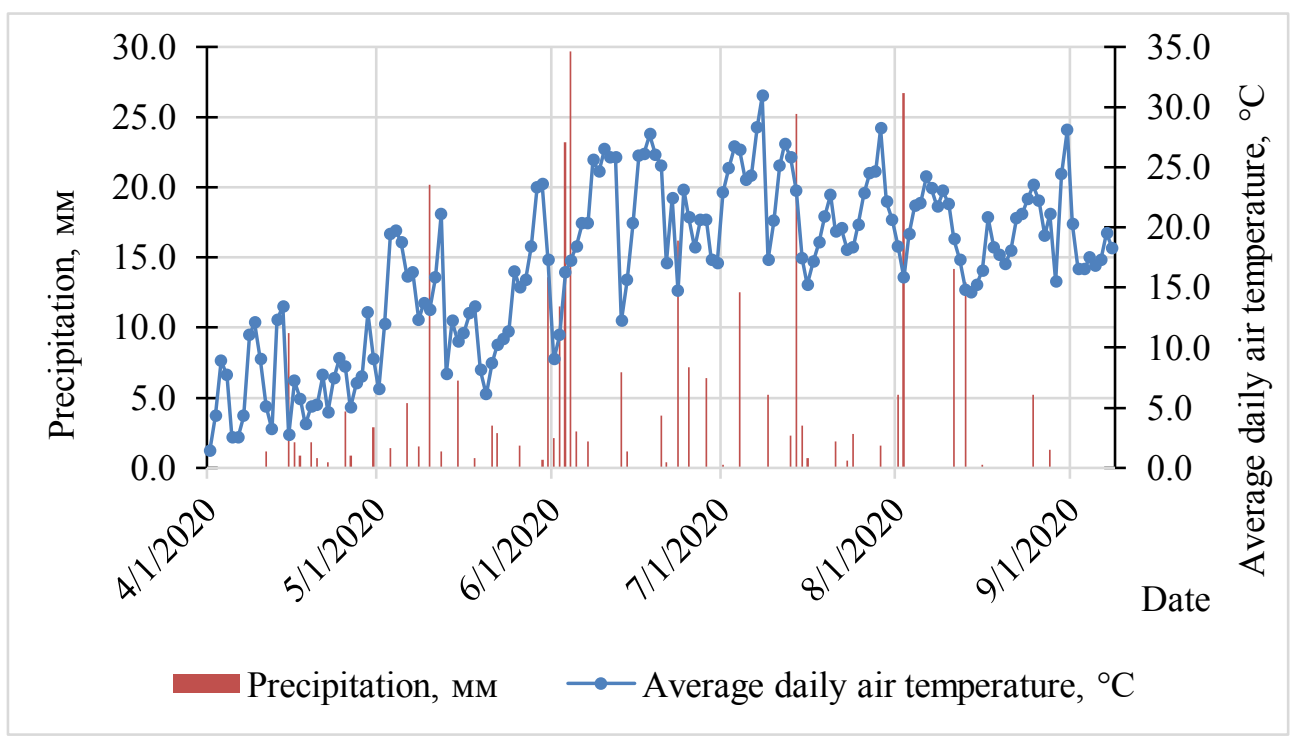

Fig. 3. Weather data for the period May - September 2020, Podvyaz, Ryazan region

\subsection{Data Processing}


The prevailing weather conditions in May and early June contributed to the slow growth of soybeans and low vegetation indices, for example, on June 11, 2020, the average index values were: NDVI - 0.395; NDRE - 0.147; GNDVI - 0.44 (Figure 4).

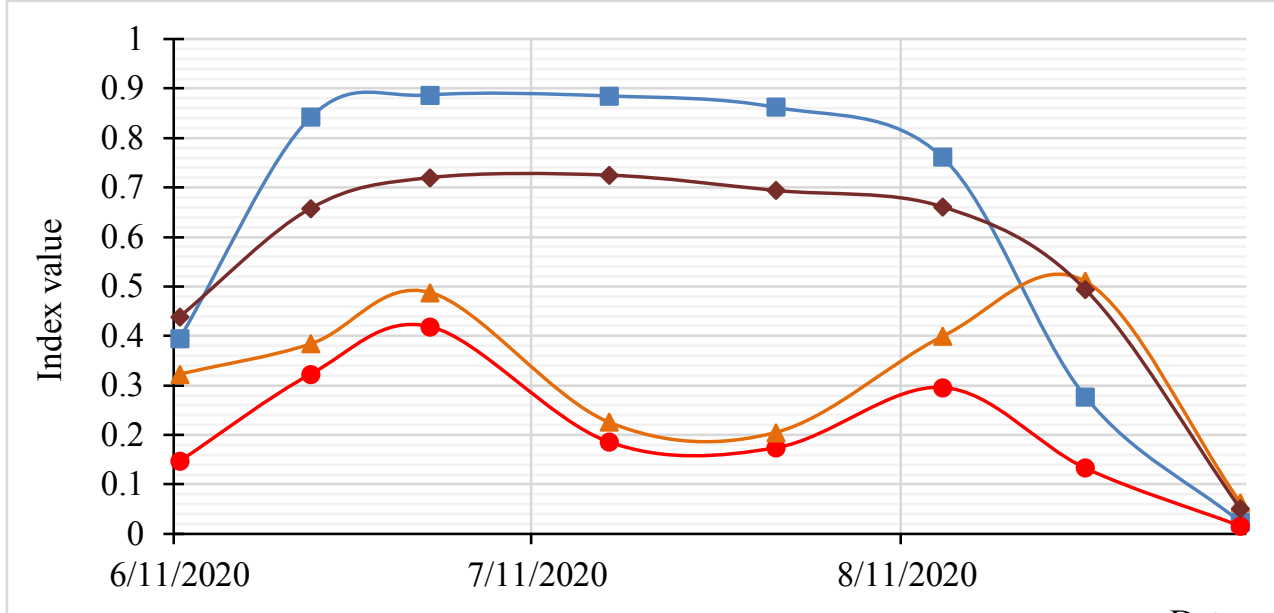

Date

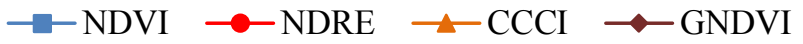

Fig. 4. Average values of vegetation indices NDVI, NDRE, CCCI, GNDVI in the main phases of soybean vegetation

To advance the growth of crops on July 2, 2020, the additional fertilizing "Raikat Development" was introduced, which is supposed to improve the stage of development and growth of new plant tissues. In the period under review from 07/02/2020 to 07/17/2020 the average values of NDVI and GNDVI remained unchanged and were $0.887 ; 0.885$ and 0.72 ; 0.725 respectively (Figure 4). The NDVI and GNDVI are statistically equal at the Student $t-$ test of 0.831424505 (the differences are considered significant at $5 \%$ significance level if tcr $\geq 2.179$, and $1 \%$ if $\mathrm{tcr} \geq 4.318$, with $\mathrm{n} 1=7 ; \mathrm{n} 2=7$ ).

The NDRE and CCCI indices were used to assess the photosynthetic activity of the vegetation cover and the saturation of leaves with nitrogen. The average values of the indices in the period from $07 / 02 / 2020$ to $07 / 31 / 2020$ indicated the presence of nitrogen starvation in crops $0.419 ; 0.186 ; 0.174$ and $0.488 ; 0.226 ; 0.205$ respectively. At the same time, feeding did not improve performance. Statistically, the differences in the mean values of these indices could be considered significant, with the Student's t-test equal to $2.394341416(\mathrm{p}=0.05)$.

After applying the second additional fertilizing "Atlante" on July 31, 2020, the average values of the NDRE and CCCI indices increased from 0.174 to 0.296 and from 0.205 to 0.399 (Figure 4). "Atlante" was a liquid fertilizer containing phosphorus and potassium. The average values of the NDRE index were statistically different from the average values of the NDVI index, with the Student's t-test equal to $5.216421165(\mathrm{p}=0.01)$.

Among the other considered indices that reflected changes in the introduction of fertilizing were the indices: ClGreen (GCI) and CVI (Figure 5). They estimated the total chlorophyll content in the plant mass, while the CVI index was more sensitive to changes in the chlorophyll content in the leaves. The CVI index values showed an increase in the period from July 31 to August 14, 2020, from 2.941 to 3.264. Statistically, the mean values of these indices were equal, with the Student's t-test $1.140571105(\mathrm{p}=0.05)$. 


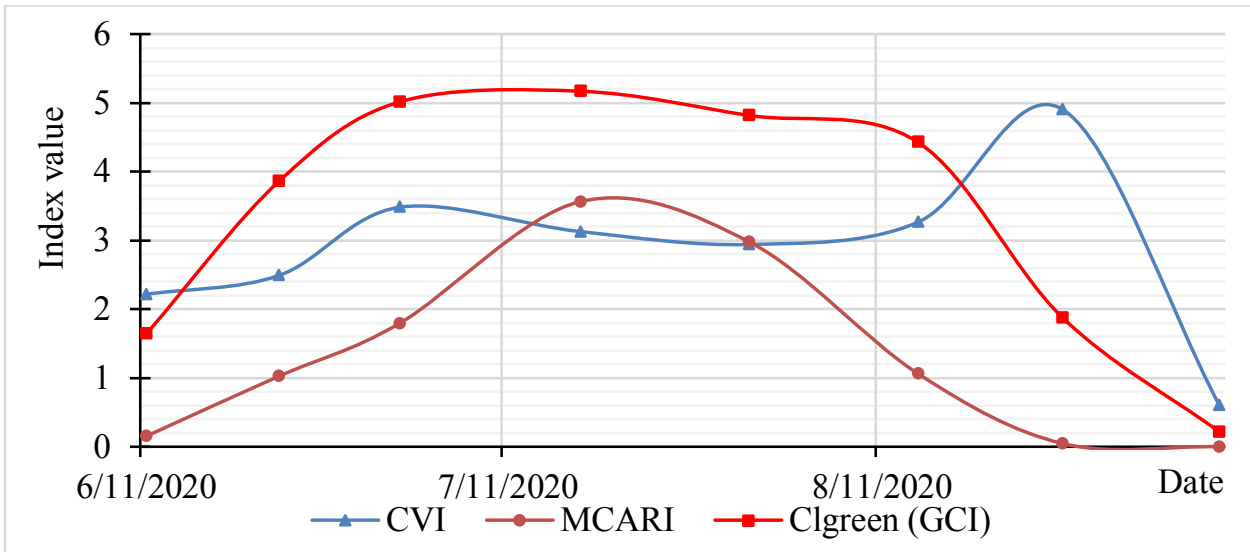

Fig. 5. Average values of vegetation indices CVI, MCARI, ClGreen (GCI) in the main phases of soybean vegetation

The average values curve of the MCARI index described the natural changes in the chlorophyll concentration in the leaves during the main phases of the growing season, without reflecting the application of fertilizing. Peak values obtained on July 17, 2020, for the MCARI index were: 3.564 .

The addition of "Atlante" did not affect the chlorophyll amount (ClGreen index (GCI)) in early maturing varieties - samples No. 1 and No. 9 in Figure 6 marked with red markers, because the crops were already in the ripening phase. While the index values in No. 3, 4, and 8 increased during the seed filling phase (Figure 6 marked with blue markers). The values comparison between the spots of early and late-ripening varieties showed that the data of the first one was statistically different from the last one, with the Student's t-test equal to $2.87521064(p=0.05)$. The values of the NDVI index also showed a sharp decrease in the phytomass index for samples 1 and 9, which breeders considered as early ripening varieties, in Figure 7 - marked with red markers.

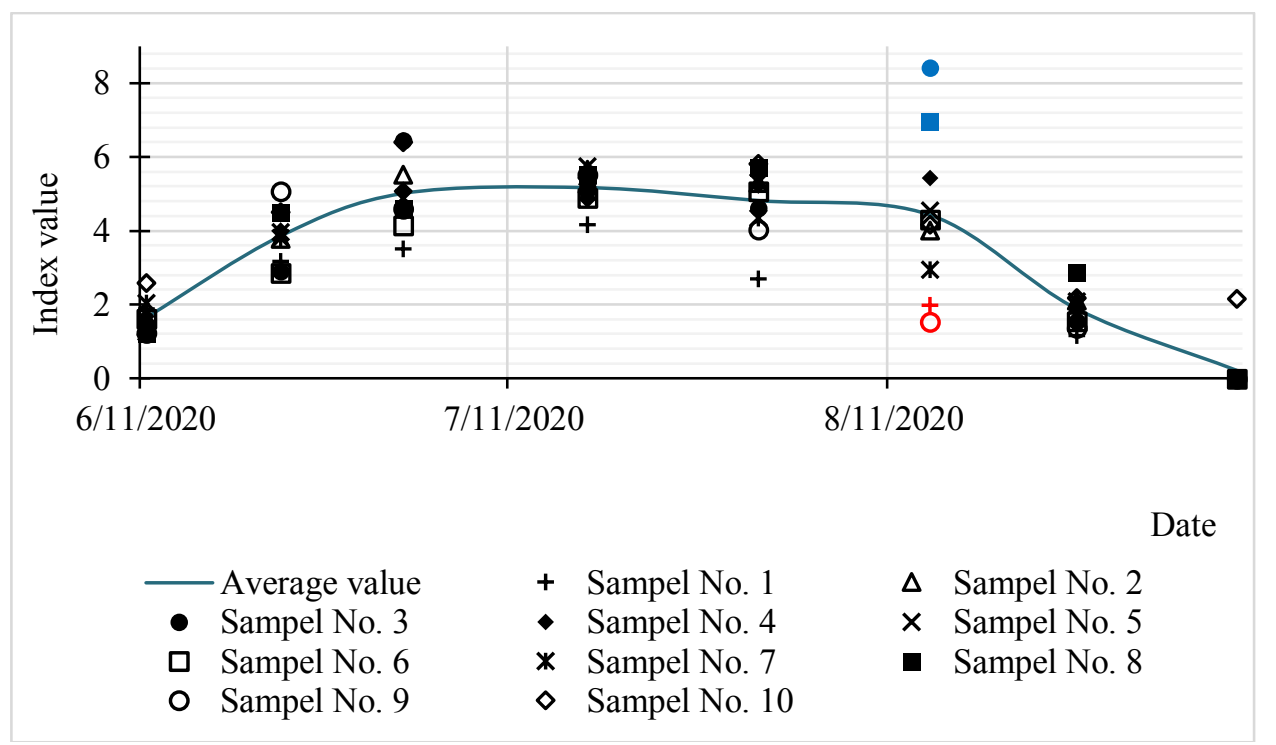

Fig. 6. Values of the ClGreen (GCI) index in the main phases of the soybean growing season 


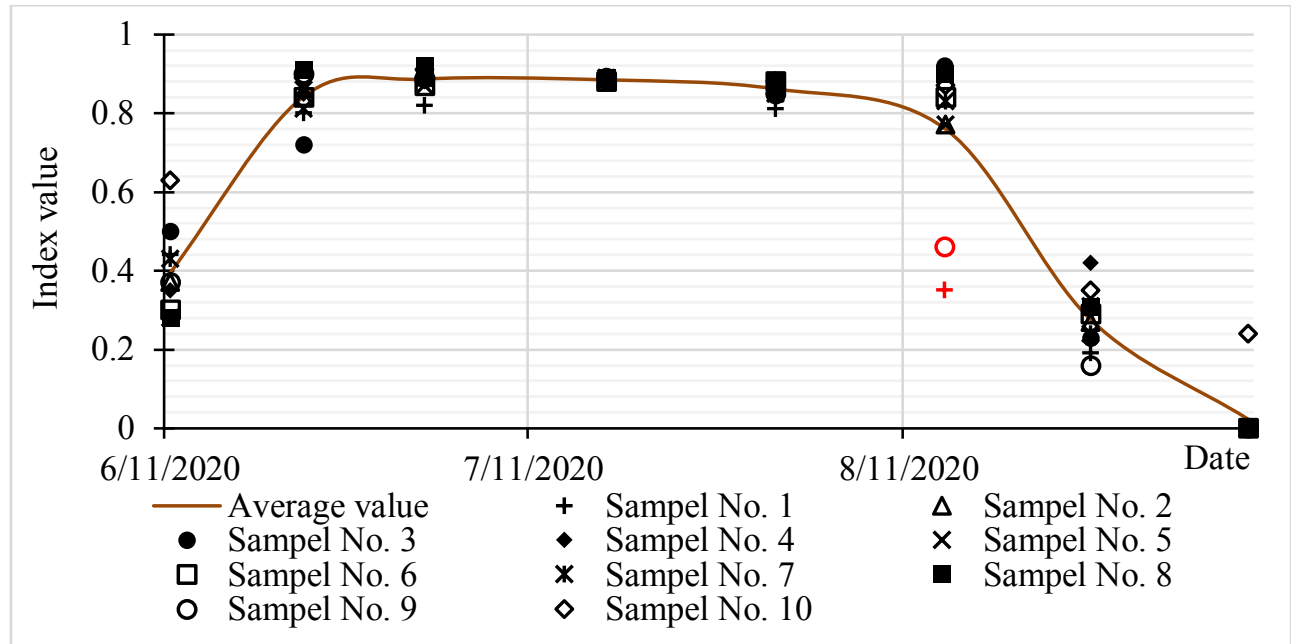

Fig. 7. Values of the NDVI index in the main phases of the soybean growing season

The difference between the samples values No. 1 and No. 10 was also shown by the GNDVI index analysis, which showed the degree of crops wilting and senescence (Figure 8). Comparison of these samples revealed that the data of No. 1 were statistically different from the data of No. 10 with the Student's t-test equal to $2.639182917(\mathrm{p}=0.05)$.

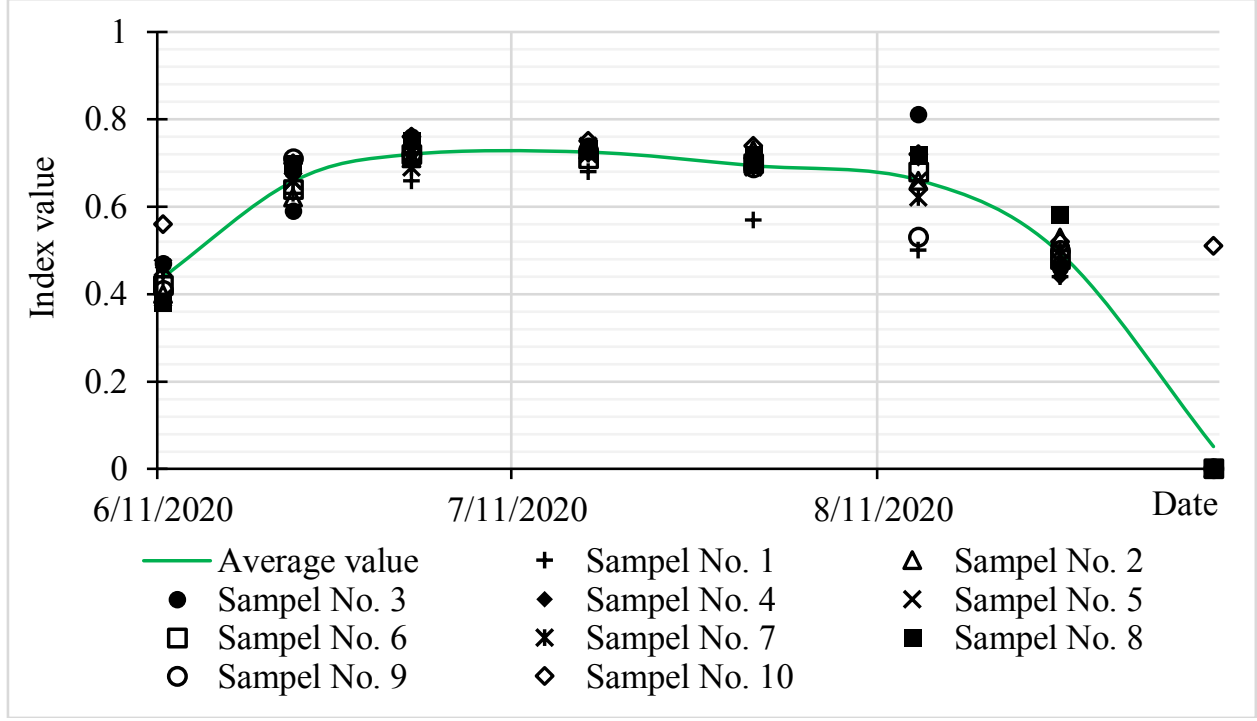

Fig. 8. Values of the GNDVI index in the main phases of the soybean growing season

The Table 2 displays the indices values that did not reflect the application of additional fertilizer, early ripening samples No. 1 and No. 9, as well as the late-ripening sample No. 10. The Table clearly shows a sharp decline in indicators for 14 days from July 31 to August 14, 2020. The difference between the values was calculated using the formula [33]:

$$
D=\frac{V I_{1}-V I_{2}}{V I_{1}} \times 100 \%
$$

where D - the difference between the vegetation indices values in percent; VI1 - the value of the vegetation index as of July 31, 2020; VI2 - the value of the vegetation index as of August 14, 2020. 
Table 2. Vegetation indices (VI) values for samples No. 1, No. 9, and No. 10

\begin{tabular}{|c|c|c|c|c|c|c|c|c|c|}
\hline \multirow{2}{*}{ VI } & \multicolumn{3}{|c|}{ Sample 1} & \multicolumn{3}{|c|}{ Sample 9} & \multicolumn{3}{|c|}{ Sample 10} \\
\hline & $\begin{array}{c}81 \\
\text { DAP }\end{array}$ & $\begin{array}{c}95 \\
\text { DA } \\
\text { P }\end{array}$ & $\begin{array}{c}\text { Difference } \\
, \% \\
\end{array}$ & $\begin{array}{c}85 \\
\mathrm{DA} \\
\mathrm{P}\end{array}$ & $\begin{array}{c}99 \\
\text { DAP }\end{array}$ & $\begin{array}{c}\text { Difference } \\
, \%\end{array}$ & $\begin{array}{c}85 \\
\text { DA } \\
\text { P }\end{array}$ & $\begin{array}{c}99 \\
\text { DA } \\
\text { P }\end{array}$ & $\begin{array}{c}\text { Difference } \\
, \%\end{array}$ \\
\hline NDVI & 0.81 & 0.35 & 56.79 & 0.85 & 0.46 & 45.88 & 0.88 & 0.87 & 1.14 \\
\hline $\begin{array}{c}\text { Clgreen } \\
(\mathrm{GCI})\end{array}$ & 2.71 & 1.97 & 27.31 & 4.04 & 1.52 & 62.38 & 5.81 & 4.17 & 28.23 \\
\hline GNDVI & 0.57 & 0.5 & 12.28 & 0.69 & 0.53 & 23.19 & 0.74 & 0.72 & 2.70 \\
\hline MCARI & 2.3 & 0.05 & 97.83 & 2.64 & 0.26 & 90.15 & 2.37 & 1.65 & 30.38 \\
\hline
\end{tabular}

For early maturing varieties samples, there was a tendency to change the values of indices (NDVI, Clgreen (GCI), GNDVI, MCARI) in the ripening phase. The vegetation index MCARI showed the largest changes. The values of the NDVI index approached the minimum for the vegetation cover, and the difference in values reached $56.79 \%$. Changes in the indices' values of the late-ripening sample were insignificant, so for NDVI and GNDVI - less than $5 \%$, the indices with a bigger difference (Clgreen (GCI) and MCARI) still had high values of chlorophyll content in plants.

Based on the obtained data, custom index formulas were derived. These indices had a statistical difference between the values of the early and late maturing samples.

ClGreen (GCI) and GNDVI formulas showing only their minimum values:

$$
\begin{gathered}
\text { ClGreen }(\mathrm{GCI})_{\min }=\left(\frac{\mathrm{NIR}}{\text { Green }}-1\right)+\frac{0}{\min }\left(0 ;\left(\frac{\mathrm{NIR}}{\text { Green }}-1\right)-2\right), \\
\mathrm{GNDVI}_{\text {min }}=\frac{\mathrm{NIR}-\mathrm{Green}}{\text { NIR+Green }}+\frac{0}{\min }\left(0 ; \frac{\text { NIR-Green }}{\text { NIR+Green }}-0.4\right),
\end{gathered}
$$

The values of 2 and 0.4 were taken as the average values of the ClGreen (GCI) and GNDVI indices of soybean crops with identified early readiness for harvest.

The vegetation maps ClGreen (GCI)min (Figure 9 a) and GNDVImin (Figure 9 b) showed crops with only the minimum amount of chlorophyll as of 08/14/2020, including samples No. 1 and No. 9 of early maturing soybean varieties. ClGreen (GCI)min and GNDVImin indices took minimum values. The maximum value of the ClGreen (GCI)min index was 2, GNDVImin - 0.4. 


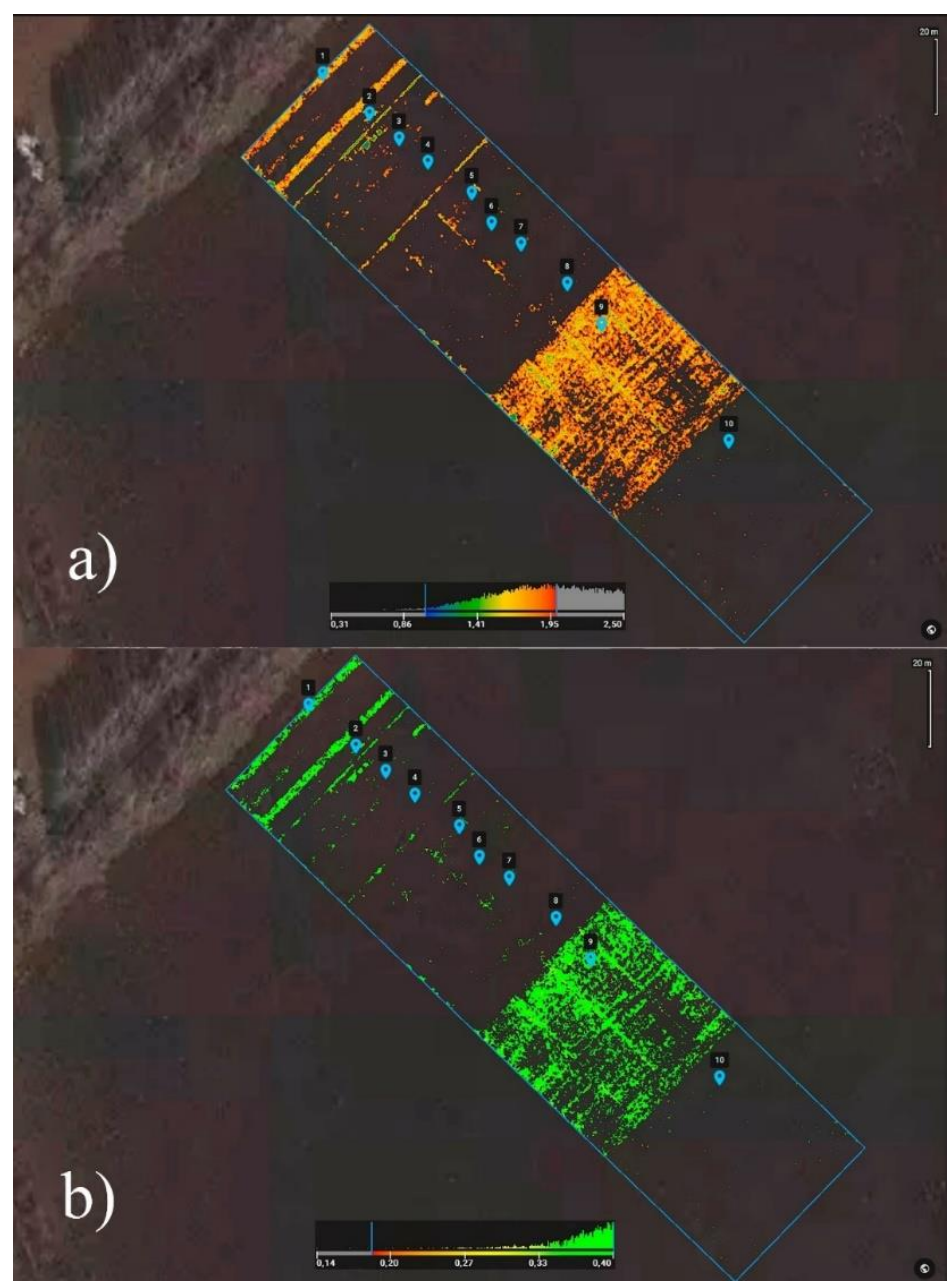

Fig. 9. Vegetation maps of crops ready for harvest a) ClGreen (GCI)min; b) GNDVImin

\section{Conclusions}

When studying the change in the chlorophyll content in the soybean leaves, seven broadband vegetation indices NDVI, NDRE, ClGreen (GCI), CCCI, CVI, GNDVI, MCARI were used. Each of these indices reacted differently to changes in the plant condition during the growing season. The alterations of the vegetation phases, weather conditions, and the application of additional fertilizer influenced the changes in the plant content. Unstable weather conditions contributed to an increase in the duration of the growing season. For early ripening varieties, the growing season was 112 days (sowing on May 8 and harvesting on August 27), which was longer than the ripening time of early ripening varieties typical for growing in the region under consideration. For example, the early ripening variety of soybean Kasatka matured in 76-85 days (according to the Register of the State Sorting Commission of the Russian Federation https://reestr.gossortrf.ru/sorts/9908136/).

Analysis of the average values of the considered indices indicates that when analyzing changes in the chlorophyll content in soybean crops, it is necessary to use a complex of several broadband vegetation indices for a comprehensive assessment of the plant state. NDVI for evaluating the general plant condition, CCCI and NDRE for recording crops 
nitrogen starvation, ClGreen (GCI), CVI or MCARI for assessing chlorophyll content in plant leaves, GNDVI for assessing wilting processes of plants.

Regular crop monitoring helped to assess the early crops' readiness for harvesting. The MCARI index showed a rapid drop in the chlorophyll content in soybean leaves. The observed change in combination with a significant decrease in the NDVI values, ClGreen (GCI), GNDVI indices testified to the early readiness of crops for harvesting.

The statistical difference between the indices of early and late maturing samples $(\mathrm{p}=0.05)$ contributed to the development of custom formulas ClGreen (GCI)min and GNDVImin. These equations were calculated to reflect only crops with the minimum chlorophyll content in the leaves. The use of the obtained formulas is advisable to determine the soybean crops early readiness for harvesting during the ripening phase, for early ripening varieties 7-10 days before the expected minimum maturity date.

\section{References}

1. Y. Zhang, Y. Li, R. Wang, L. Xu, M. Li et al., Frontiers in Plant Science 11, 1244 (2020) doi:10.3389/fpls.2020.01244

2. N.B. Claypool, J.H. Lieth, Scientia Horticulturae 268, 109371 (2020) doi:10.1016/j.scienta.2020.109371

3. M. Yuan, J.C. Burjel, J. Isermann, N.J. Goeser and C.M. Pittelkow, Journal of Soil and Water Conservation 74(4), 350-359 (2019) doi:10.2489/jswc.74.4.350

4. L.G.T. Crusiol, M.R. Nanni, R.H. Furlanetto, R.N.R. Sibaldelli, E. Cezar et al., International Journal of Remote Sensing 41(9), 3243-3265 (2020) doi:10.1080/01431161.2019.1673914

5. Y.A. Yan, L. Deng, X.L. Liu and L. Zhu, Remote Sensing 11(23), 2753 (2019) doi:10.3390/rs11232753

6. X. Zhang, J. Zhao, G. Yang, J. Liu, J. Cao at el., Remote Sensing 11(23), 2752 (2019) doi:10.3390/rs11232752

7. D. Li, J.M. Chen, X. Zhang, Y. Yan, J. Zhu et al., Remote Sensing of Environment 248, 111985 (2020) doi:10.1016/j.rse.2020.111985

8. H.C. Bazame, F.A.C. Pinto, D.S. Queiroz, D.M. De Queiroz and D. Althoff, Tropical Grasslands-Forrajes Tropicales 8(2), 60-71 (2020) doi:10.17138/TGFT(8)60-71

9. A.B. Tekin, M. Fornale, Turkish Journal of Agriculture and Forestry 43(3), 288-298 (2019) doi:10.3906/tar-1806-1

10. L. Zhao, Y. Shi, B. Liu, C. Hovis, Y. Duan at el., Remote Sensing 11(24), 3012 (2019) doi:10.3390/rs11243012

11. R.L. Davis II, J.K. Greene, F. Dou, Y.-K. Jo, T.M. Chappell, Agronomy 10(5), 633 (2020) doi:10.3390/agronomy10050633

12. A.A. Artyushin, R.K. Kurbanov, L.A. Marchenko and O.M. Zakharova, Electrical technologies and electrical equipment in the agro-industrial complex 4(37), 36-43 (in Russian with an abstract in English) (2019)

13. R.K. Kurbanov, N.I. Zakharova and O.M. Gayduk, Electrical technologies and electrical equipment in the agro-industrial complex 3(40), 87-94 (in Russian with an abstract in English) (2020) doi:10.22314/2658-4859-2020-67-3-87-94

14. D.J. Mulla, Biosystems Engineering SI 114(4), 358-371 doi:10.1016/j.biosystemseng.2012.08.009 
15. M. Yang, M.A. Hassan, K. Xu, C. Zheng, A. Rasheed et al., Frontiers in Plant Science 11, 927 (2020) doi:10.3389/fpls.2020.00927

16. J.R. Xue, B.F. Su, Journal of Sensors, 1353691 (2017) doi:10.1155/2017/1353691

17. N. Lu, W.H. Wang, Q.F. Zhang, D. Li, X. Yao et al., Frontiers in Plant Science 10, 1601 (2019) doi:10.3389/fpls.2019.01601

18. T. Ahamed, L. Tian, Y. Zhang, K.C. Ting, Biomass \& Bioenergy 35(7), 2455-2469 (2011) doi:10.1016/j.biombioe.2011.02.028

19. T. Merrick, M.L.S.P. Jorge, T.S.F. Silva, S. Pau, J. Rausch et al., International Journal of Remote Sensing 41(17), 6755-6782 (2020) doi:10.1080/01431161.2020.1750731

20. P.D. Liu, R.H. Shi and W. Gao, Earth Science Informatics 11(1), 147-156 (2018) doi:10.1007/s12145-017-0319-1

21. S. Liu, H.Y. Yu, M.C. Chen, Z.J. Piao, T. Yu et al., Spectroscopy and Spectral Analysis 40(5), 1575-1580 (2020) doi:10.3964/j.issn.1000-0593(2020)05-1575-06

22. J. Yue, H. Feng, Q. Tian, C. Zhou, Plant Methods 16, 104 (2020) doi:10.1186/s13007020-00643-Z

23. B. Boiarskii, H. Hasegawa, Journal of Mechanics of Continua and Mathematical Sciences SI 4, 20-29 (2019) doi:10.26782/jmcms.spl.4/2019.11.00003

24. M. Yuan, J.C. Burjel, J. Isermann, N.J. Goeser and C.M. Pittelkow, Journal of Soil and Water Conservation 74(4), 350-359 (2019) doi:10.2489/jswc.74.4.350

25. J. Zhou, J. Zhou, H. Ye, Md. Ali, H. Nguyen et al., Computers and Electronics In Agriculture, 175, 105576 (2020) doi:10.1016/j.compag.2020.105576

26. J. Zhou, D. Yungbluth, C.N. Vong, A. Scaboo and J. Zhou, Remote Sensing, 11(18), 2075 (2019) doi:10.3390/rs11182075

27. E.V. Tyutereva, V.A. Dmitrieva and O.V. Voitsekhovskaja, Agricultural Biology, 52(5), 843-855 (2017) doi:10.15389/agrobiology.2017.5.843eng

28. I. Borra-Serrano, T. De Swaef, P. Quataert, J. Aper, A. Saleem et al., Remote Sensing 12(10), 1644 (2020) [doi:10.3390/rs12101644].

29. M. Maimaitijiang, A. Ghulam, P. Sidike, S. Hartling, M. Maimaitiyiming et al., ISPRS Journal of Photogrammetry and Remote Sensing 134(43), 58 (2017) doi:10.1016/j.isprsjprs.2017.10.011

30. M. Maimaitijiang, V. Sagan, P. Sidike, S. Hartling, F. Esposito et al., Remote Sensing of Environment 237, 111599 (2019) doi:10.1016/j.rse.2019.111599

31. P. Ranđelović, V. Đorđević, S. Milić, S. Balešević-Tubić, K. Petrović, et al., Agronomy 10(8), 1108 (2020) doi:10.3390/agronomy10081108

32. I.G. Smirnov, R.K. Kurbanov, M.A. Litvinov, O.M. Zakharova, N.I. Zakharova et al., RU 2728846 C1 (2020)

33. S. Dutta, S.K. Singh, S. Panigrahy, Journal of the Indian Society of Remote Sensing 42(2), 353-361 (2014) do1:10.1007/s12524-013-0325-9 